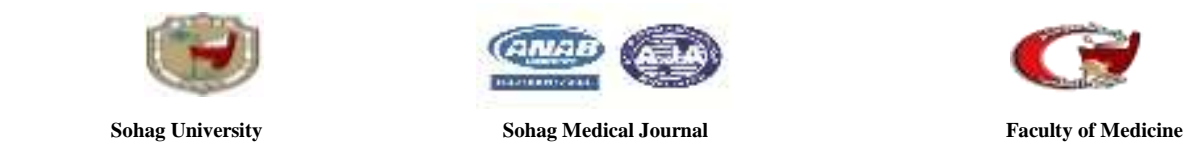

\title{
Comparison of thyroid hormones level in normal and preeclamptic pregnancy
}

\author{
Ahmed Salah Eldeen Abdal Latif, salah Roshdy, Mohamed \\ Nour El-Dien, Mohamed Yahya Abdel Hafez, Wael Abd el- \\ hameid aly, \\ Obstetrics and gynecology, Sohag faculty of medicine, Sohag university \\ clinical pathology department faculty of medicine that university
}

\section{Abstract}

To find a relationship between preeclampsia and thyroid dysfunction by comparing serum levels of Free T3 (fT3), Free T4 (fT4) and TSH in preeclampsia and normal pregnancy.

The study was conducted within 6 months from May 2018 to November 2018, on the patients who attended the OB/GYN department of Sohag Faculty of Medicine, Institutional review board approval was obtained April 2017.

30 of them were diagnosed as preeclamptic [blood pressure after 20 weeks of gestation is raised to 140/90 $\mathrm{mm}$ of $\mathrm{Hg}$ or more or have mean Blood Pressure. (diastolic $+1 / 3$ rd pulse pressure) of more than $110 \mathrm{~mm}$ of $\mathrm{Hg}$ ] with the presence of proteinuria and/or edema. 30 age-matched normotensive pregnant women. Blood pressure was measured (auscultatory and palpatory) in a semi-sitting position using a sphygmomanometer. Both groups had no history of thyroid dysfunction.

According to the International Society for the Study of Hypertension Pre-eclampsia is defined as blood pressure $\geq 140 / 90 \mathrm{mmHg}$ on two separate occasions 6 hours apart or a single recording of diastolic blood pressure of $110 \mathrm{mmHg}$, in association with proteinuria $\geq 1+$ on dipstick urine testing (Dawn C. Scantlebury, et al., 2013)

Keywords: THYROID, PREECLAMPSIA, PREGNANCY, Hypothyroidism

\section{INTRODUCTION:}

During pregnancy, many hormonal changes occur as an increase in estrogen, human chorionic gonadotropin, human chorionic somatotropin, prolactin and decrease in thyroxine. maternal thyroid hormone excess or deficiency can affect maternal and fetal outcomes at all stages of pregnancy and can interfere with ovulation and fertility.

Pregnancy has a main effect on thyroid gland function as the following, Serum beta-hCG, which rises sharply in early pregnancy, is closely related structurally to serum TSH, so cross-reactivity at the receptor stimulates thyroid hormone release and suppresses serum TSH levels. During the second trimester, serum beta-hCG levels decrease and increase serum TSH. Also, elevated estrogen levels lead to an increase the level of Thyroxine Binding Globulin (TBG), which is leading to an increase in thyroxine $\left(\mathrm{TT}_{4}\right)$ levels. During the $1 \mathrm{st}$ trimester, Tri-iodothyronine $\left(\mathrm{TT}_{3}\right)$ and $\mathrm{TT}_{4}$ reach a concentration of $30-100 \%$ of pre-pregnancy levels. Changes in the free hormone levels are however controversial (fig. 1). thyroid hormone synthesis starts only after 14 weeks of gestation. Thyroid hormones and Thyroid-stimulating hormone (TSH), are the cornerstone in confirming the diagnosis of thyroid disorders ${ }^{1}$. 
SOHAG MEDICAL JOURNAL

Vol. 24 No. 1 Jan 2020

\section{AIM OF THE WORK:}

comparison of the serum levels of Free $\mathrm{T}_{3}\left(\mathrm{fT}_{3}\right)$, Free $\mathrm{T}_{4}\left(\mathrm{fT}_{4}\right)$ and $\mathrm{TSH}$ in preeclampsia and normal pregnancy to find a relationship between the development of preeclampsia and thyroid dysfunction.

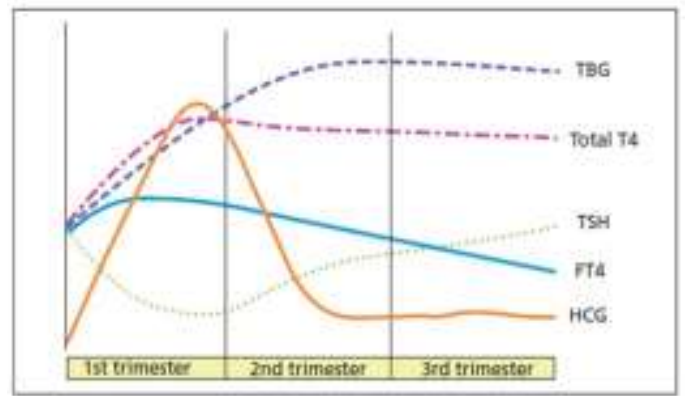

(figure 1): Thyroid physiology during pregnancy

\section{PATIENTS AND METHODS:}

The study was conducted within 6 months from May 2018 to November 2018 , on the patients who attended the OB/GYN department of Sohag Faculty of Medicine, Institutional review board approval was obtained April 2017.

- Inclusion criteria: Pregnant women with:

- Age:16-38 years.

- Known to be normotensive before pregnancy.

- Pregnant 28-34 week of gestation

- Singleton pregnancy.

- No previous history of thyroid dysfunction.

- Exclusion criteria: Pregnant women with:

- Age less than 20 years and more than 35 years.

- Multiple pregnancies.

- History of hypertension, renal disease, chronic liver disease. pre-existing heart disease and any metabolic disease before pregnancy, Gestational diabetes and those with a $\mathrm{BMI} \geq$ of $30 \mathrm{Kg} / \mathrm{m} 2$.
- Any history of treatment with drugs such as L-thyroxin that may affect thyroid function.

The study included 60 subjects divided into two groups; preeclamptic group and control group.

- 30 of them were diagnosed as preeclamptic [after 20 weeks of gestation, blood pressure is raised to $140 / 90 \mathrm{~mm}$ of $\mathrm{Hg}$ or more or have mean Blood Pressure more than 110 $\mathrm{mm}$ of $\mathrm{Hg}$ (diastolic+1/3rd pulse pressure)] with the presence of proteinuria and/or edema.

- 30 age-matched normotensive pregnant women. Blood pressure was measured (auscultatory and palpatory) in a semisitting position using a sphygmomanometer. Both groups had no history of thyroid dysfunction.

According to the International Society for the Study of Hypertension, the definition of Pre-eclampsia as the following blood pressure $\geq 140 / 90$ $\mathrm{mmHg}$ should be recorded on two separate occasions 6 hours apart or a single recording of diastolic blood pressure of $110 \mathrm{mmHg}$, in association with proteinuria $\geq 1+$ on dipstick urine testing ${ }^{2}$. In all enrolled women an informed written consent was taken after explanation of the nature of the study and the following was done:

1-Thorough history taking: including personal history, date of last menstrual period, obstetric history, and family history with a special careful search for risk factors.

\section{2- Examination:}

- General Examination:

- Blood pressure was measured in a semi-recumbent position $45^{\circ}$ head up with a standard mercury sphygmomanometer with an appropriate-sized cuff at the level of 
SOHAG MEDICAL JOURNAL

Vol. 24 No. 1 Jan 2020
Comparison of thyroid hormones level in normal

Ahmed Salah eldeen the heart. The supported right arm used consistently, Blood pressure was measured on two measurements taken 6 hours apart, the first phase of Korotkoff sounds was used to define systolic blood pressure and diastolic blood pressure was defined by the fifth phase of Korotkoff sounds because it corresponds to intraarterial pressure.

- Chest and heart examination.

- Calculation of BMI by measuring weight in Kilogram divided by the square of height in meters.

- Edema was tested for pitting in the lower limb (ankles and shin of the tibia) checking for edema of the lower abdomen.

- Obstetric examination. Abdominal and local examination.

3-Ultrasound:

For documentation of fetal viability, calculate gestational age and fetal biometry, placental location, amniotic fluid volume and exclude multiple pregnancies.

4-Investigations:

FreeT3, free $\mathrm{T}_{4}$, and $\mathrm{TSH}$ were measured by the electrochemiluminescence immunoassay "ELISA" (Elecsys 2010 and Cobas e 411 analyzers) $2 \mathrm{ml}$ venous blood sample was obtained from each subject in the case and normal groups.

\section{Ethical considerations:}

Informed consent had been taken and describe the nature of the research to participants and freedom of choice about participating in the research. Protection of patient privacy and data security had been emphasized.

\section{RESULTS:}

the 60 women were included, 30 of them were normal pregnant women in the control group and in the other group, 30 preeclampsia women were enrolled.

\begin{tabular}{|l|l|l|l|}
\hline & $\begin{array}{l}\text { Hypertensive } \\
\text { No 30 }\end{array}$ & $\begin{array}{l}\text { Normotensive } \\
\text { No 30 }\end{array}$ & $\begin{array}{l}\text { P- } \\
\text { Value }\end{array}$ \\
\hline Age & $23.69 \pm 4.8$ & $25.3 \pm 4.2$ & 0.103 \\
\hline Parity & $2.09 \pm 0.89$ & $2.67 \pm 2.28$ & 0.182 \\
\hline $\begin{array}{l}\text { Gestational } \\
\text { age(weeks) }\end{array}$ & $34.14 \pm 2.80$ & $34.07 \pm 3.40$ & 0.93 \\
\hline $\begin{array}{l}\text { Free } \mathbf{T}_{3} \\
(\mathbf{p g} / \mathbf{m l})\end{array}$ & $4.07 \pm 0.78$ & $3.53 \pm 0.50$ & 0.006 \\
\hline $\begin{array}{l}\text { Free } \mathbf{T}_{\mathbf{4}} \\
(\mathbf{n g} / \mathbf{d l})\end{array}$ & $0.99 \pm 0.28$ & $1.12 \pm 0.2$ & 0.001 \\
\hline $\begin{array}{l}\text { TSH } \\
(\boldsymbol{\mu I U} / \mathbf{m l})\end{array}$ & $5.18 \pm 4.09$ & $1.96 \pm 1.23$ & 0.002 \\
\hline
\end{tabular}

Table (1): A comparison between preeclamptic and normotensive subjects

The mean age of cases was $23.69 \pm 4.8$ years and the mean age of control was $25.3 \pm 4.2$ years $(\mathrm{P}-$ value $=0.103)$.

Both groups were matched as regards the parity $(2.09 \pm 0.89)$ in the case group and $(2.67 \pm 2.28)$ in the control group (P-value 0.182). In comparing the gestational age of both groups, there was no difference in statistical significance. In the case group it was $(34.14 \pm 2.80)$, while in the control group; it was $(34.07$ \pm 3.40 ) (P-value:0.93).

Our study showed that mean Free Triiodothyronine $\left(\mathrm{fT}_{3}\right)$ in study group was $4.07 \pm 0.78 \mathrm{pg} . / \mathrm{ml}$ and in control was $3.53 \pm 0.50 \mathrm{pg} . / \mathrm{ml}(\mathrm{P}$-value $=0.006)$. As regard Mean Free Thyroxine $\left(\mathrm{fT}_{4}\right)$; in study group it was $0.99 \pm 0.28 \mathrm{ng} / \mathrm{dl}$ and in control group it was $1.12 \pm 0.20$ $\mathrm{ng} / \mathrm{dl}(\mathrm{P}$-value $=0.0016)$.

Mean Thyroid Stimulating Hormone (TSH) in the study group was $5.18 \pm$ $4.09 \mu \mathrm{IU} / \mathrm{ml}$ which is statistically different from that of the control group which was $1.96 \pm 1.23 \mu \mathrm{IU} / \mathrm{ml}$ (P-value $<0.001)$.

In conclusion, statistical analysis showed that there was significant difference in the $\mathrm{fT}_{4}(\mathrm{p}$-value $=0.0016)$ $\& \mathrm{fT}_{3}$ (p-value $\left.=0.0058\right)$ levels in normal pregnancy and in preeclampsia. There was a significant increase in TSH levels 
SOHAG MEDICAL JOURNAL

Vol. 24 No. 1 Jan 2020 in pre-eclamptic patients (P-value $<0.001$ ).

However, there was no statistically significant difference in the $\mathrm{fT}_{4} \& \mathrm{fT}_{3}$ and TSH levels in comparing cases of mild PET with those of severing PET (Table 2).

\begin{tabular}{|c|c|c|c|}
\hline & $\begin{array}{l}\text { Mild } \\
\text { PET }\end{array}$ & $\begin{array}{l}\text { Severe } \\
\text { PET }\end{array}$ & $\begin{array}{l}\text { P- } \\
\text { value }\end{array}$ \\
\hline Free $\mathrm{T}_{3}$ & $\begin{array}{l}3.54 \quad \pm \\
0.52\end{array}$ & $4.07 \pm 0.78$ & 0.0286 \\
\hline Free $_{\mathrm{T} 4}$ & $\begin{array}{l}1.03 \\
0.28\end{array}$ & $0.99 \pm 0.28$ & 0.0628 \\
\hline $\begin{array}{l}\text { TSH } \\
(\mu \mathrm{IU} / \mathrm{ml})\end{array}$ & $\begin{array}{ll}3.6 & \pm \\
1.28 & \\
\end{array}$ & $5.18 \pm 4.09$ & 0.0730 \\
\hline
\end{tabular}

Table (2) comparison of $\mathrm{fT}_{3}, \mathrm{fT}_{4}$ and TSH levels in patients of the hypertensive group between those with mild PET and those with severe PET

Mean $\mathrm{FT}_{3}$ in cases of mild PET was 3.54 $\pm 0.52 \mathrm{pg} . / \mathrm{ml}$ and in severe PET was $4.07 \pm 0.78 \mathrm{pg} . / \mathrm{ml}$ (P-value $=0.0286)$. Mean $\mathrm{FT}_{4}$ in cases of mild PET $1.03 \pm$ $0.28 \mathrm{ng} / \mathrm{dl}$ and in severe PET was $0.99 \pm$ $0.28 \mathrm{ng} / \mathrm{dl}$ (P-value $=0.0628)$. $\mathrm{Mean} \mathrm{TSH}$ in cases of mild PET $3.6 \pm 1.28 \mu \mathrm{IU} / \mathrm{ml}$ and in severe PET was $5.18 \pm 4.09$ $\mu \mathrm{IU} / \mathrm{ml}(\mathrm{P}$-value $=0.0730)$.

\section{DISCUSSION}

Many factors may play an important role in the development of preeclampsia. Etiology of preeclampsia still clearly unknown, and it may occur in the second or the third trimester of pregnancy ${ }^{3}$. Some studies showed a relation between the levels of thyroid hormones and the development of preeclampsia.

In our study, the results showed a high prevalence of hypothyroidism about $(44.8 \%)$ in preeclamptic women and (7\%) in control. These findings supported the previous reports that showed, a preeclamptic woman had a higher incidence of biochemical hypothyroidism in comparison to normotensive pregnant woman ${ }^{4}$

Our study showed that TSH level was a significant increase in the preeclamptic group as compared to controls; as the following mean TSH $5.18 \pm 4.09 \mu \mathrm{IU} / \mathrm{ml}$ ((p-value <0.001). There was significant difference fT3 and fT4 levels in preeclamptic cases were lower in comparison to the controls $\mathrm{fT}_{4}$ (pvalue $=0.0016) \& \mathrm{fT}_{3}$ (p-value $\left.=0.0058\right)$. No significant difference could be detected in the $\mathrm{fT}_{4} \& \mathrm{fT}_{3}$ and TSH levels in cases of mild and severe PET also we did not have any case with hyperthyroidism in both groups. our results were not matching the finding of other studies 5 .

Many studies showed that there was an obvious relation between thyroid hormones and the development and severity of preeclampsia 6 .

Another study explained that no significant difference in the $\mathrm{T} 4(\mathrm{p}=0.08)$ \& T3 $(\mathrm{p}=0.49)$ levels in normal pregnancy and in preeclampsia. There was a significant increase in TSH levels in preeclamptic patients $(\mathrm{p}=0.0001) 7$

Various other studies with different findings with relation to T4 (Low and high levels of T4) and TSH levels (High levels of TSH) in preeclamptic 8 .

The present study showed that no significant difference in the fT4\& fT3 and TSH levels in cases of mild and severe PET, which are not in agreement with findings of other studies, 9. Severe preeclamptic women showed significantly higher T4 and T3 levels compared to healthy ones $(\mathrm{p}=0.0001$ and $\mathrm{p}=0.001$ ).

Also Kharb S, et al.10 showed that the thyroid function is not changed in severe preeclampsia.

Severe preeclamptic women showed T4 and T3 levels significantly higher than 
mild ones $(\mathrm{p}=0.0001$ and $\mathrm{p}=0.0001)$. This means that thyroid dysfunction may lead to the development of preeclampsia from mild to severe. This may explain the pathological alterations and unusual secretion of thyroid tissue that may lead to T3 and T4 synthesis and secretion.

There are many suggestions such as pathogens of preeclampsia that may be due to endothelial dysfunction, decreased alteration of $\mathrm{T} 4$ to $\mathrm{T} 3$ and placental dysfunction 11 .

According to Steegers et al 12, the pathophysiology of hypertensive disorders during pregnancy could be explained as increased levels of thyroid hormone that can cause endothelial cell dysfunction.

Different geographical areas, races, and diets may be the cause of differences in our study with other findings.

It has been suggested that reduced concentration of thyroid hormones in preeclampsia may be due to the loss of protein-bound hormones in the urine.

Lao et al reported that hypothyroidism in preeclampsia (decreased levels of FT4 and increased levels of TSH) leads to vascular smooth muscle contraction both in systemic and renal vessels that lead to increased diastolic hypertension, peripheral vascular resistance, and decreased tissue perfusion 13.

The pathogenesis of preeclampsia could be explained as the following, Thyroid dysfunction can be associated with proteinuria, which leads to increase excretion of thyroxine and thyroidbinding globulins163, Endothelial dysfunction is a central pathogenic feature in women with preeclampsia, which may lead to multiple system disorder during human pregnancy 14. Elevated levels of circulating VEGER-1 concentration in preeclamptic women which result in decreased circulating levels of free VEGF and PIGF, which is the cause of an anti-angiogenic state and causing endothelial cell dysfunction 15 . TBG levels increase in pregnancy due to high estrogen levels also it could explain the elevated TT3 and TT4 levels observed in some studies., it is postulated that conversion of $\mathrm{T} 4$ to $\mathrm{T} 3$ in the liver is hampered which can account for low fT3 levels observed in preeclamptic patients so fT3 and fT4 levels remain normal. In preeclampsia.

During preeclampsia, decreased the peripheral conversion of $\mathrm{T} 4$ to $\mathrm{T} 3$ resulting from hepatic and renal involvement that also leads to increased loss of proteins and protein-bound hormones in the urine in preeclamptic so that there is decreased T3 levels 16. Also, increased fetal demand lead to a low T3 level, the placenta break-down and transfer of maternal T4 to the fetus which lead to decrease fT4 levels in preeclamptic women $(\mathrm{p}<0.01) 17$.

There is a case report remission of preeclampsia after correction of hypothyroidism treated by thyroxine supplementation at gestational age 29 weeks and after 4 weeks stoppage of combined antihypertension treatment, alpha dopa then after another 5 weeks, ( at 34 weeks), even nifedipine. Since the blood pressure remained normal without any antihypertensive, probably in this woman subclinical hypothyroidism may be the cause of preeclampsia and its treatment cured pregnancy-induced hypertension 18.

However, no enough evidence is justified to determine whether screening and treatment for subclinical hypothyroidism in asymptomatic women according to the American College of Obstetricians and Gynecologists 19. According to Spong, routine screening 
SOHAG MEDICAL JOURNAL

Vol. 24 No. 1 Jan 2020 of all pregnant women remains unwarranted 20.

Limitation of the study:

Our study had some limitations within which our findings need to be interpreted carefully. As the following:

First, as in most empirical studies, there was a chance of recall bias in the process of gathering data. Given the low income and low socioeconomic status of the pregnant women of this study, it was not feasible to carry out longitudinal studies and follow up on the thyroid hormones postpartum.

Second, the results of this study may not be completely generalizable because the sample was restricted.

Third, our study did not examine the impact of treatment of the cases with hypothyroidism.

\section{REFERENCES:}

1.Aynadis Alemu, Betelihem Terefe, Molla Abebe and Belete Biadgo: Thyroid hormone dysfunction during pregnancy: A review. Int. J. Reprod Biomed (Yazd). 2016; 14(11): 677-686.

2.Dawn C. Scantlebury, Gary L. Schwartz, Letitia A. Acquah, Wendy M. White, Marvin Moser, and Vesna D. Garovic: The Treatment of Hypertension During Pregnancy: When Should Blood Pressure Medications Be Started?. Curr Cardiol Rep. 2013 Nov; 15(11): 10.1007/s11886-013-0412-0.

3.Leona C. Poon* and Kypros H. Nicolaides: Early Prediction of Preeclampsia. Obstet Gynecol Int.; 2014: 297397.

4.Kumar A, Ghosh BK, Murthy NS.: Maternal thyroid hormonal status in preeclampsia. Indian J Med Sci. 2005; 59:57 63

5.Männistö T, Vääräsmäki M, Pouta A, Hartikainen AL, Ruokonen A, Surcel HM, Bloigu A, Järvelin MR, Suvanto E. Thyroid dysfunction and autoantibodies during pregnancy as predictive factors of pregnancy complications and maternal morbidity in later life. J Clin Endocrinol Metab. 2010 Mar;95(3):1084-94.

6.Ipadeola A, Nkwocha G C, Adeleye J O: Subclinical hypothyroidism unmasked by preeclampsia and ascites, Indian J. of Endocrinol.metabol. 2013;17(7):173-175.

7.Manjunatha, Basavraja, Ramesh S Patil, Thyroid Dysfunction in Pregnancy and Preeclampsia. Scholars Journal of Applied Medical Sciences (SJAMS) 2014; 2(6G):3349-3352

8.Sahu, M.T., V. Das, S. Mittal, A. Agarwal, and M. Sahu: Overt and subclinical thyroid dysfunction among Indian pregnant women and its effect on maternal and fetal outcome. Arch. Gynecol. Obstet. 2010;28(1):215-220

9.Levine RJ, Vatten LJ, Horowitz GL, Qian C: Pre-eclampsia, soluble FMS-like tyrosine kinase 1, and the risk of reduced thyroid function: nested case-control and population-based study. BMJ. 2009; 339: b4336.

10..Kharb S, Sardana D., and Nanda S.: Correlation of Thyroid Functions with Severity and Outcome of Pregnancy. Ann Med Health Sci Res. 2013; 3(1): 43-46.

11.L Harshvardhan, SS Dariya, Aradhana Sharma, Lalita Verma: Study of Association of Thyroid Hormone in PreEclampsia and Normal Pregnancy, J. Ass. Physic. India, 2017; 65:44-

12.Steegers, E.A., P. von Dadelszen, J.J. Duvekot, and Stillman IE, Karumanchi SA. The glomerular injury of preeclampsia. J Am Soc Nephrol 2007; 18:2281.

13.Anitha K Satyanarayan, Veena $\mathrm{H}$ Chandregowda, Manjunath Hemberal, Raju H Taklikar: Maternal thyroid profile in pre-eclampsia. International Journal of Medical Science and Public Health. 2015; 4 (10): 1401-1403.

14.Banik A, Kandilya D, Ramya S, Stünkel W, Chong YS, Dheen ST: Maternal Factors that Induce Epigenetic Changes Contribute to Neurological Disorders in Offspring. Genes (Basel). 2017 24;8(6): 150 
SOHAG MEDICAL JOURNAL

Vol. 24 No. 1 Jan 2020

15.Camille E. Powe, Richard J. Levine, and S. Ananth Karumanchi: Preeclampsia, a Disease of the Maternal Endothelium. The Role of Antiangiogenic Factors and Implications for Later Cardiovascular Disease. J. Circulation. 2011;123: 28562869

16.Lucia Maria Procopciuc, Gabriela Caracostea, Georgeta Hazi, Georgiana Nemeti \& Florin Stamatian: D2Thr92Ala, thyroid hormone levels and biochemical hypothyroidism in preeclampsia. J. Gynecol. Endocrinol. 2017; 33 (2):136-140.

17.Subramanian Kannan, Shriram Mahadevan, and Alben Sigamani: A Systematic Review on Normative Values of Trimester-specific Thyroid Function Tests in Indian Women; Indian $\mathbf{J}$ Endocrinol Metab. 2018; 22(1): 7-12.
18.Sahu T Meenakshi et al; Case Report Resolution of pre-eclampsia following correction of hypothyroidism, J Obstet Gynecol India 2009; 59, 6: 589-590.

19.Amy J. Blatt, Jon M. Nakamoto, and Harvey W. Kaufman: National Status of Testing for Hypothyroidism during Pregnancy and Postpartum. J. Clin. Endocrinol. \& Metabol.,2012; 97 (3): 777-784,

20.Johns LE, Ferguson KK, McElrath TF, Mukherjee B, Seely EW, Meeker JD.: Longitudinal Profiles of Thyroid Hormone Parameters in Pregnancy and Associations with Preterm Birth. PLoS ONE, 2017; 12(1): e0169542. DOI:10.1371/journal. pone.0169542 